\title{
Management of neurogenic bowel dysfunction in the community after spinal cord injury: a postal survey in the United Kingdom
}

\author{
M Coggrave ${ }^{1,2}$, C Norton ${ }^{2,3}$ and J Wilson-Barnett ${ }^{3}$ \\ ${ }^{1}$ National Spinal Injuries Centre, Stoke Mandeville Hospital, Aylesbury, Bucks, UK; ${ }^{2}$ Burdett Institute of Gastrointestinal Nursing, \\ King's College, London, UK and ${ }^{3}$ The Florence Nightingale School of Nursing and Midwifery, King's College, London, UK
}

\begin{abstract}
Study design: Postal survey.
Objectives: To describe bowel management in community-dwelling spinal cord-injured (SCI) individuals and to explore associations between age, injury, dependency, problems, interventions and satisfaction.

Setting: Outpatients of a single $\mathrm{SCl}$ unit, in the United Kingdom.

Methods: Postal questionnaire to all outpatients with $\mathrm{SCl}$ for at least 1 year, of any level or density, aged 18 years or more.

Results: Response rate was 48.6\% $(n=1334)$. Median age was 52 years, median duration of injury 18 years. The most common intervention was digital evacuation (56\%). Up to 30 min was spent on each bowel care episode by $58 \%$ of respondents; $31-60 \mathrm{~min}$ by $22 \% ; 14 \%$ spent over $60 \mathrm{~min}$. Reported problems included constipation (39\%), haemorrhoids (36\%) and abdominal distension (31\%). Reduced satisfaction with bowel function was associated with longer duration of each bowel care episode, faecal incontinence, greater number of interventions used and more problems reported (all $P \leqslant 0.001) ; 130(9.7 \%)$ had undergone any type of surgical bowel intervention. Impact of bowel dysfunction on the respondent's life was rated as significantly greater than other aspects of $\mathrm{SCl}$ $(P \leqslant 0.001)$.

Conclusions: Managing SCl bowel function in the community is complex, time consuming and remains conservative. Despite potential for bias from a low response, for this large group of responders, bowel dysfunction impacted most on life compared with other SCl-related impairments. The study findings demand further exploration of bowel management to reduce impact, minimize side effects and increase the choice of management strategies available.
\end{abstract}

Spinal Cord (2009) 47, 323-333; doi:10.1038/sc.2008.137; published online 18 November 2008

Keywords: neurogenic bowel; bowel management; community setting; spinal cord injury

\section{Introduction}

Bowel dysfunction is a significant consequence of spinal cord injury (SCI) resulting in faecal incontinence and severe constipation. ${ }^{1,2}$ These dysfunctions necessitate regular, frequent and often demanding programmes of management. Bowel management and associated problems have been increasingly recognized as important factors in post-injury community reintegration and quality of life..$^{3-5}$

The purpose of this study was to describe bowel management in community-dwelling individuals with an SCI in the United Kingdom and to explore associations between age, injury characteristics, dependency, problems, interventions and satisfaction.

Correspondence: Dr M Coggrave, The National Spinal Injuries Centre, Stoke Mandeville Hospital, Mandeville Road, Aylesbury, Bucks HP21 8AL, UK. E-mail: maureen.coggrave@buckshosp.nhs.uk

Received 23 October 2007; revised 29 September 2008; accepted 4 October 2008; published online 18 November 2008

\section{Materials and methods}

A questionnaire was developed following interviews with a convenience sample of 24 SCI individuals. These interviews explored what methods of bowel management were used and what issues were of importance. Themes were analysed and a questionnaire was devised and piloted with 12 patients to ensure comprehension, with amendments made to compose the final questionnaire (Appendix 1). All outpatients of the study centre (a specialist tertiary SCI centre) with SCI following trauma or acute onset disease, injured more than 1 year and over 18 years of age, were surveyed $(n=2960)$. This was a postal questionnaire, sent with a patient information sheet and an invitation to participate, whether or not bowel problems were being experienced, to the patient's home address, with a covering explanatory letter and a stamped addressed return envelope. Those who did not respond within 4 weeks were sent a single reminder. Data were stored and analysed using the Statistics Package for the Social Sciences (SPSS Inc., Chicago, IL, USA). 
Categorical data were examined using the Pearson $\chi^{2}$ test and odds ratios were calculated where appropriate. Correlations were conducted using Spearman's $\rho$. Friedman's test was used to look for differences between scores given for impact on aspects of daily life. The Wilcoxon test was used to explore the significance of these differences; due to the number of comparisons, a Bonferroni correction was applied and significance was set at $P=0.002$ for these tests. We certify that all applicable institutional and governmental regulations concerning the ethical involvement of human volunteers were followed during the course of this research.

\section{Results}

The response rate was $48.6 \%(n=1334)$. Non-responders were significantly younger than responders. Responders were more likely to have thoracic rather than other levels of injury compared with non-responders. There was no difference in gender between responders and non-responders. Demographic details are shown in Table 1 . Men accounted for $73.4 \%$ of respondents. Injury characteristics are shown in Table 2. 'Complete' or 'incomplete' injury was as reported by the patient on the questionnaire and was not verified in any other way. Data from individuals with sacral and lumbar injuries are combined throughout because of the very few individuals with sacral lesions.

\section{Reported bowel management}

Most respondents (72\%) had been conducting their reported method of bowel care for more than 5 years. Interventions reported are shown in Figure 1. Many responders reported that more than one intervention was used.

Stimulant laxatives were used by $36 \%$ of the sample, osmotics $15 \%$, bulk formers $6 \%$ and stool softeners $3 \%$.

Table 1 Age and injury duration of respondents

\begin{tabular}{lrrcr}
\hline & $\mathrm{n}$ & Minimum & Maximum & Median \\
\hline Age at study in years & 1334 & 19 & 91 & 51.5 \\
Duration of injury in years & 1326 & 1 & 65 & 17.6 \\
Age at injury in years & 1326 & $<1$ & 85 & 27.4 \\
\hline
\end{tabular}

Table 2 Reported completeness of injury (\% of each level of injury ${ }^{a}$ )

\begin{tabular}{lcccccccc}
\hline & Complete & $\%$ & Incomplete & $\%$ & Unknown & $\%$ & \multicolumn{2}{c}{ Total } \\
\hline Cervical & 218 & 40.7 & 289 & 53.9 & 34 & 5.4 & 541 & 100 \\
Thoracic & 399 & 61.4 & 207 & 31.8 & 63 & 6.8 & 669 & 100 \\
Lumbar & 23 & 21.5 & 70 & 65.4 & 19 & 13 & 112 & 100 \\
Sacral & 0 & 0 & 1 & 25.0 & 3 & 75 & 4 & 100 \\
Missing & & & & & 8 & & 8 & 0.6 \\
Total & 640 & & 567 & & 127 & & 1334 & \\
\hline
\end{tabular}

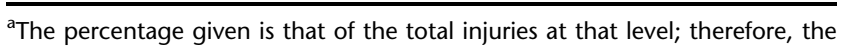
rows summate to $100 \%$, but not the columns.
Rectal stimulants were used by $59.6 \%$, often in combination with digital stimulation or manual evacuation (Table 3). Management was conducted daily (41\%) or on alternate days (33\%), completed in $15 \mathrm{~min}$ by $36 \%$ of the sample, $16-30 \mathrm{~min}$ by $22.4 \%$ and $31-60 \mathrm{~min}$ by $22 \%$, more than $60 \mathrm{~min}$ by $14 \%$ ( $6 \%$ unknown). The median number of different interventions used was 3 (range 0-11). The most common was digital evacuation (56\%); of those who used digital stimulation, $76 \%$ also used digital evacuation.

Few respondents had undergone any type of bowel surgery (9.7\% in total, 6.8\% excluding haemorrhoid-related procedures). Seven individuals reported a sacral anterior root stimulator. One individual reported an antegrade continence enema. Colostomy was reported by $2.4 \%$ of respondents (excluded from remainder of analysis).

\section{Problems associated with bowel care}

Reported problems are shown in Table 4. Only $1.5 \%$ of respondents reported no bowel problems (median 2 problems, range 0-9). People reporting more bowel problems were likely to report a longer duration of bowel care $(P<0.001)$ and greater number of interventions used $(P<0.001)$. More than one-third reported haemorrhoids. The concept of flexibility in the bowel programme emerged during questionnaire development interviews. Many respondents (35\%) felt that they were 'not very flexible' ('I do not usually change my routine unless it is unavoidable') or 'not flexible at all' ('I will not go to activities if they clash with my bowel management time').

To assess the impact of bowel dysfunction on daily life, respondents scored statements as shown in Table 5. Aspects of SCI were rated according to impact on daily life (impact scores $0-10$, where $10=$ most impact) (see Table 6). Scores allocated to the different aspects varied significantly $(P=0.001)$. Impact scores for bowel function were significantly greater $(P<0.001)$ than those for all other rated aspects. Low or no flexibility was associated with greater impact of bowel management.

Twenty per cent of respondents were dissatisfied or very dissatisfied with bowel management. Low satisfaction was associated with longer duration of care $(P<0.001)$, more frequent incontinence $(P<0.001)$, more frequent management $(P=0.008)$, more problems $(P<0.001)$ and more interventions used $(P<0.001)$. Higher satisfaction was associated with greater flexibility $(P<0.001)$. Digital evacuation, anorectal stimulation, abdominal distension, pain, constipation and haemorrhoids were all associated $(P<0.001)$ with dissatisfaction with management.

\section{Interventions and outcomes}

Relationships between interventions and outcomes are summarized in Table 7. Constipation, abdominal pain, abdominal distension and haemorrhoids were each associated with greater use of interventions, increased frequency of autonomic dysreflexia and increased duration of bowel care (all $P<0.001$ ). 


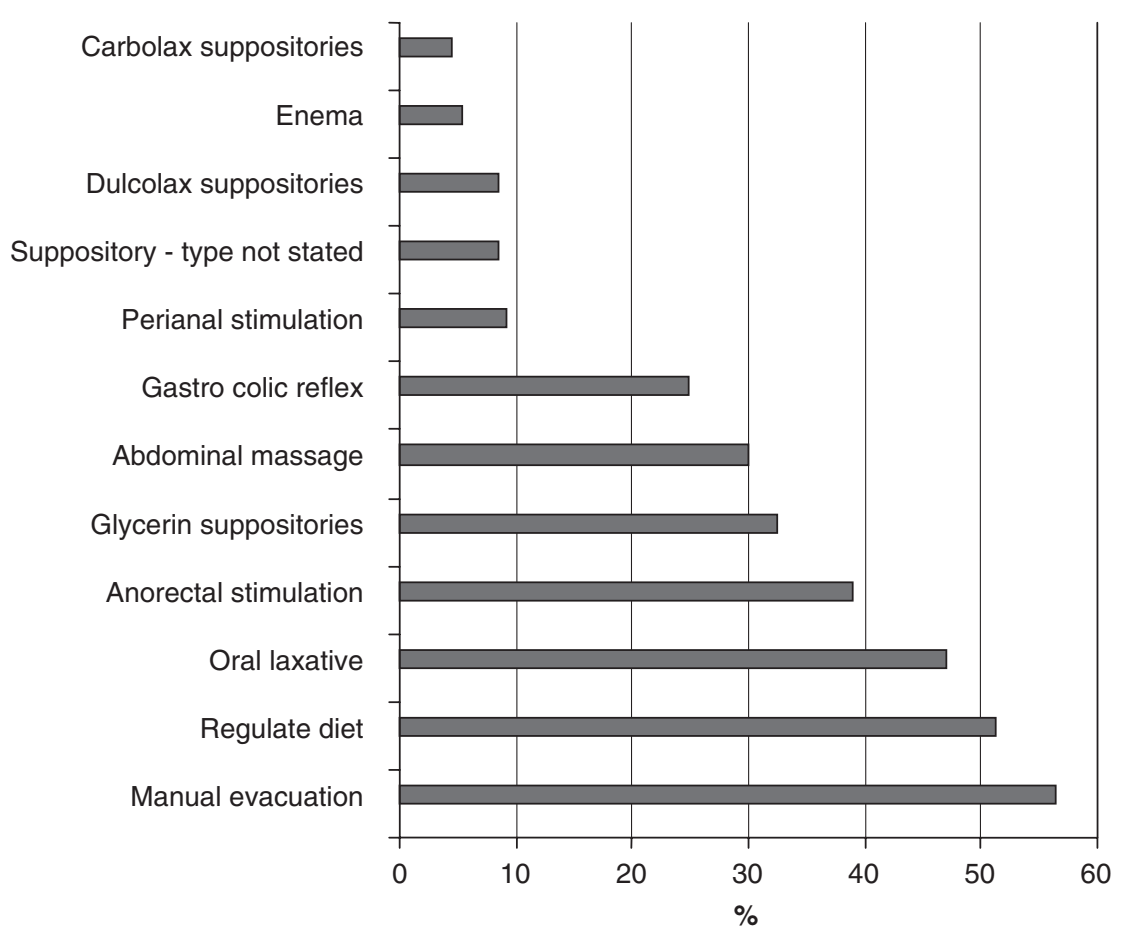

Figure 1 Interventions used for bowel care (multiple responses possible).

Table 3 Combined use of suppositories and digital interventions $(n=1334)^{\mathrm{a}}$

\begin{tabular}{lccc}
\hline Rectal stimulant type & $\begin{array}{c}\text { Suppository use } \\
\mathrm{n}\end{array}$ & $\begin{array}{c}\text { Suppository } \\
\text { with digital stimulation } \\
\mathrm{n}\end{array}$ & $\begin{array}{c}\text { Suppository with manual evacuation } \\
\mathrm{n}\end{array}$ \\
\hline Glycerin & 434 & 222 & 270 \\
Dulcolax & 114 & 62 & 67 \\
Carbolax & 61 & 37 & 37 \\
Type not known & 114 & 55 & 68 \\
Enema & 73 & 35 & 45 \\
Total & $796(59.6 \%)$ & $411(51.6 \%)$ & $487(61.1 \%)$ \\
\hline
\end{tabular}

apercentages are proportion of those using each combination who used the specific product named.

Table 4 Reported problems with bowel care $(n=1334)$

\begin{tabular}{lcc}
\hline & Frequency & \% of respondents \\
\hline Constipation & 522 & 39.1 \\
Haemorrhoids & 485 & 36.4 \\
Abdominal distension & 409 & 30.7 \\
Abdominal pain & 268 & 20.1 \\
Duration of bowel care $>60$ min & 185 & 13.9 \\
Surgery to bowel & 130 & 9.8 \\
Incontinence at least monthly & 112 & 8.4 \\
AD often/always & 108 & 8.1 \\
$\quad$ AD often/always-lesions above T7 only & 93 & 9.5 \\
AD occasionally-lesions above T7 only & 348 & 35.6 \\
No flexibility in routine & 101 & 7.6 \\
Anal fissure & 96 & 7.2 \\
Rectal prolapse & 55 & 4.1 \\
Other & 58 & 4.3 \\
& & \\
Total & 2529 & \\
\hline
\end{tabular}

Abbreviation: AD, autonomic dysreflexia.

\section{Dependency}

Some help with bowel care was needed by $11.8 \%$ of respondents, whereas a complete assistance was required by $22.8 \%$. Unsurprisingly, individuals with complete cervical injuries were more likely to require complete assistance than any other group $(P<0.001)$. Care was provided by nurses $(23.8 \%)$, personal carers $(30 \%)$ or partners (32\%).

Those needing assistance used more interventions $(P<0.001)$, spent more time and had more problems $(P<0.001)$; complete care was associated with less satisfaction $(P=0.02)$. Assistance with bowel care was associated with fitting life around bowel management, bowel management interfering with working, greater impact on relationships, staying away from home, social life, feeling that bowel management was a problem and with increased ratings of how much bowel care affected life (all $P<0.001)$. 
Table 5 Reported effect of bowel management on life activities

\begin{tabular}{|c|c|c|c|c|c|c|c|c|c|c|c|c|}
\hline & \multicolumn{2}{|c|}{ Fit life around bowel care } & \multicolumn{2}{|c|}{ Stops me working } & \multicolumn{2}{|c|}{ Interferes with relationships } & \multicolumn{2}{|c|}{ Prevents staying away from home } & \multicolumn{2}{|c|}{ Its a problem } & \multicolumn{2}{|c|}{ Affects social life } \\
\hline & $\mathrm{n}$ & $\%$ & $\mathrm{n}$ & $\%$ & $\mathrm{n}$ & $\%$ & $\mathrm{n}$ & $\%$ & $\mathrm{n}$ & $\%$ & $\mathrm{n}$ & $\%$ \\
\hline Not at all & 501 & 37.6 & 865 & 64.8 & 821 & 61.5 & 714 & 53.5 & 528 & 39.6 & 704 & 52.8 \\
\hline A little & 488 & 36.6 & 198 & 14.8 & 279 & 20.9 & 295 & 22.1 & 507 & 38.0 & 399 & 29.9 \\
\hline A lot & 277 & 20.8 & 105 & 7.9 & 102 & 7.7 & 222 & 16.6 & 212 & 15.9 & 133 & 10.0 \\
\hline Total & 1266 & 94.9 & 1168 & 87.6 & 1583 & 90.1 & 1231 & 92.3 & 1247 & 93.5 & 1236 & 92.7 \\
\hline
\end{tabular}

Table 6 Mean impact scores (0-10 where 10 is the greatest impact)

\begin{tabular}{lc}
\hline Assessed aspect of spinal cord injury & Mean scores \\
\hline Bowel function & 4.72 \\
Sexual function & 4.70 \\
Bladder function & 4.19 \\
Wheelchair use & 3.99 \\
Pain & 3.74 \\
Spasticity & 3.42 \\
Skin care & 3.24 \\
\hline
\end{tabular}

\section{Individual and injury characteristics}

Associations between respondents' characteristics and bowel management outcomes are summarized in Table 8 .

Level of injury. Respondents with cervical injuries reported greater use of dietary manipulation $(P=0.02)$, gastrocolic reflex, glycerin suppositories, all laxatives and stimulant laxatives (all $P<0.001)$. Those with thoracic injuries reported significantly greater use of digital evacuation $(P=0.001)$ and abdominal massage $(P=0.003)$. A higher level of injury was associated with using more interventions $(P<0.001)$, longer duration of bowel care $(P \leqslant 0.001)$, less frequent care $(P \leqslant 0.001)$ and less flexibility $(P<0.001)$. Individuals with higher lesions were more likely to report abdominal pain $(P=0.02)$, distension $(P<0.001)$ and constipation $(P<0.03)$. Haemorrhoids were reported more frequently by individuals with lumbar/sacral and thoracic lesions than by individuals with cervical injuries $(P<0.001)$. Those with lumbar/sacral lesions were most likely to report daily or weekly incontinence $(P<0.001)$.

Density of injury. Individuals with incomplete injuries used fewer interventions, less time, were more likely to conduct bowel management less than twice a week, adopt an upright posture and report flexibility in their routine than those with complete lesions (all $P<0.001$ ).

Gender. Men used more dietary manipulation $(P=0.004)$, anorectal stimulation $(P=0.04)$ and suppositories $(P=0.009)$ than women. Women reported more problems than men $(P=0.002)$, including abdominal pain $(P=0.001)$, distension $(P<0.001)$, constipation $(P<0.001)$ and were more likely to use pads $(P<0.001)$. Women were less likely to receive care from a partner and more likely to receive care from a nurse than men $(P=0.004)$.
Duration of injury and age. Increasing duration of injury was associated with greater use of digital evacuation $(P<0.001)$, bisacodyl suppositories $(P=0.001)$, sodium acid phosphate and sodium bicarbonate suppositories $(P=0.05)$ and reduced use of glycerin suppositories $(P<0.001)$. Laxative use was increased $(P \leqslant 0.02)$ but stimulant laxatives specifically were not increased.

Greater age was associated with increased use of digital evacuation $(P \leqslant 0.001)$, laxatives $(P \leqslant 0.001)$, stimulant laxatives specifically $(P \leqslant 0.02)$, reduced use of glycerin suppositories $(P=0.001)$, using fewer interventions $(P=0.007)$, reduced flexibility $(P \leqslant 0.001)$ and more abdominal pain $(P=0.01)$. There may be a degree of confounding between the two variables of age and duration of injury.

\section{Discussion}

This study reports a large sample of community-dwelling SCI individuals with stable bowel management. The sample was not recruited from a health-care setting, giving the possibility of a more balanced representation of bowel care in the community than in a sample recruited from hospital attendees. However, we recognize that there is a major possibility of response bias, especially as the response rate was below 50\%. It seems likely that responders would tend to have more bowel problems than non-responders and our reported results should be read with this in mind.

Although the acceptability of digital evacuation has been questioned by some authors, ${ }^{6}$ it was the most frequently reported intervention and was clearly associated with better outcomes in independent individuals with thoracic lesions, as suggested elsewhere. ${ }^{7}$ However, causation cannot be ascribed to this association from our data. Less reported use of digital evacuation and associated increased duration of bowel care among individuals with cervical lesions may be due to the reluctance of carers, who may see digital evacuation as a last resort. Anorectal stimulation was reported to be used by fewer than half of the individuals who had reflex bowel function; it did not eradicate the need for digital evacuation and was associated with a longer duration of care. Earlier authors ${ }^{8}$ have suggested that anorectal stimulation could replace the use of suppositories once bowel care was well established; the findings of this study suggest that this technique should be thoroughly evaluated in each individual. Rectal stimulants alone were frequently insufficient to achieve complete evacuation and additional digital interventions were usually required. 
Table 7 Associations between interventions and outcomes (only significant associations are shown)

\begin{tabular}{|c|c|c|c|c|c|c|c|c|c|}
\hline & Haemorrhoids & $\begin{array}{l}\text { Faecal } \\
\text { incontinence }\end{array}$ & $\begin{array}{l}\text { Rectal } \\
\text { prolapse }\end{array}$ & Abdominal pain & Abdominal distension & Constipation & Duration & $\begin{array}{l}\text { Autonomic } \\
\text { dysreflexia }\end{array}$ & Anal fissure \\
\hline $\begin{array}{l}\text { Manual } \\
\text { evacuation }\end{array}$ & $\begin{array}{l}\text { L/S } P=0.02, \\
\text { OR } 2.6 \\
\text { T } P=0.05, \text { OR } 1.3\end{array}$ & & & $\begin{array}{l}C P=0.006, \\
\text { OR } 1.78 \\
\text { T } P=0.03 \\
\text { OR } 1.6\end{array}$ & $\begin{array}{l}C P \leqslant 0.001 \\
\text { OR } 2 \\
\text { T } P=0.055 \text { OR } 1.5\end{array}$ & $C<0.01$ OR 1.6 & $\begin{array}{l}C \text { Longer } P \leqslant 0.001 \\
\text { T Shorter } P \leqslant 0.001\end{array}$ & $C P \leqslant 0.001$ & $\begin{array}{l}P \leqslant 0.001 \\
\text { OR } 2.4\end{array}$ \\
\hline $\begin{array}{l}\text { Anorectal } \\
\text { stimulation }\end{array}$ & $\begin{array}{l}C P \leqslant 0.001 \\
\text { OR } 2 \\
\text { T } P \leqslant 0.001, \text { OR } 1.7\end{array}$ & & & $\begin{array}{l}P=0.002 \\
\text { OR1.5 }\end{array}$ & $\begin{array}{l}\mathrm{C}<0.001, \text { OR } 2.1 \\
\mathrm{~T} P=0.002, \text { OR } 1.7\end{array}$ & & $\begin{array}{l}\mathrm{C} \text { and } \mathrm{T} \\
\text { Longer } \\
P \leqslant 0.001 \\
\mathrm{LS} P=0.009\end{array}$ & $\begin{array}{l}\text { Less } \\
\text { dysreflexia } \\
P \leqslant 0.001\end{array}$ & $\begin{array}{l}C P=0.006 \\
\text { OR } 2\end{array}$ \\
\hline Laxatives & $\begin{array}{l}\text { T } P=0.02 \\
\text { OR } 1.4\end{array}$ & $\begin{array}{l}\text { Stimulant } \\
C P \leqslant 0.001 \\
T P=0.01\end{array}$ & $\begin{array}{l}\text { Stool } \\
\text { bulking } \\
\text { agent } \\
P=0.01\end{array}$ & $\begin{array}{l}\text { All laxatives-C } \\
P=0.01 \\
\text { OR } 1.75 \\
\text { T } P=0.008, \\
\text { OR } 1.7, \mathrm{SL} \\
P=0.008, \text { OR } 3 \\
\text { Stimulant } \\
\text { C } P=0.004, \\
\text { OR } 1.9 \\
\text { T } P=0.05 \\
\text { OR } 1.6 \\
\text { L/S } P=0.02, \\
\text { OR } 3.2\end{array}$ & $\begin{array}{l}\text { All laxatives-C } \\
\text { and } T P \leqslant 0.001, \\
\text { OR } 2, \\
\text { Stimulant } C \\
P=0.001, \\
\text { OR } 1.9 \\
\text { T } P \leqslant 0.001, \text { OR } 3.2 \\
\text { stool bulking agents } \\
C P=0.01, \text { OR } 2.5, \\
\text { Softeners C } \\
P=0.05, \text { OR } 3\end{array}$ & $\begin{array}{l}\text { All }-C P=0.002 \\
\text { OR } 1.8 \\
\text { T } P \leqslant 0.001 \text { OR } 2.5 \\
\text { Stimulant C } \\
P=0.02 \text { OR } 1.5 \\
\text { T } P \leqslant 0.001 \text { OR } 2.2 \\
\text { L/S } P=0.001 \\
\text { OR } 5.1\end{array}$ & $\begin{array}{l}\text { Any laxative } \\
\text { Longer } C \text { and } T \\
P \leqslant 0.001 \\
\text { Stimulant } \\
\text { Longer } \\
C \text { and } T P \leqslant 0.001\end{array}$ & $\begin{array}{l}\text { Stimulant } \\
P \leqslant 0.005\end{array}$ & \\
\hline $\begin{array}{l}\text { Chemical rectal } \\
\text { stimulants }\end{array}$ & $\begin{array}{l}\text { T Glycerin } P \leqslant 0.001 \text {, } \\
\text { OR } 1.5, \\
\text { C Dulcolax } P=0.02 \text {, } \\
\text { OR } 1.7\end{array}$ & $\begin{array}{l}\text { Dulcolax } \\
P=0.01 \\
\text { Enema } \\
P=0.01\end{array}$ & $\begin{array}{l}\text { Enema } \\
P=0.01\end{array}$ & $\begin{array}{l}\text { Dulcolax } P=0.002 \\
\text { Enema } P=0.01 \text {, } \\
\text { OR } 2\end{array}$ & & $\begin{array}{l}\text { Enema } C P=0.003 \\
\text { OR } 2.8\end{array}$ & $\begin{array}{l}\text { All } \\
\text { Longer } \\
P \leqslant 0.001\end{array}$ & $\begin{array}{l}\text { Dulcolax } \\
P \leqslant 0.001 \\
\text { Enema } 0.002 \\
\text { Carbolax } \\
P=0.008\end{array}$ & \\
\hline $\begin{array}{l}\text { Abdominal } \\
\text { massage }\end{array}$ & $\begin{array}{l}\text { C } P=0.03, \text { OR } 1.5 \\
\text { T } P=0.01, \text { OR } 1.5\end{array}$ & & & $\begin{array}{l}C P=0.002, \\
\text { OR } 1.8 \\
\text { T } P=0.001 \\
\text { OR } 2\end{array}$ & $\begin{array}{l}\text { C } P \leqslant 0.001, \text { OR } 2.6 \\
\text { T } P \leqslant 0.001, \text { OR } 2.2 \\
\text { L/S } P=0.04 \text { OR } 2.9\end{array}$ & $\mathrm{~T} P \leqslant 0.001$, OR 1.9 & $\begin{array}{l}C \& T \\
\text { Longer } \\
P \leqslant 0.001 \\
P=0.02\end{array}$ & $\begin{array}{l}\text { Less } \\
\text { dysreflexia } \\
\text { C } P \leqslant 0.001 \\
\text { T } P=0.01\end{array}$ & $\mathrm{~T} P=0.007$ OR 2.3 \\
\hline $\begin{array}{l}\text { Gastrocolic } \\
\text { reflex }\end{array}$ & $\begin{array}{l}\text { T } P=0.001 \\
\text { OR } 1.8\end{array}$ & & & $\begin{array}{l}C P \leqslant 0.001 \text {, } \\
\text { OR 0.4-pain } \\
\text { reduced }\end{array}$ & $C P=0.001$, OR 1.5 & $\begin{array}{l}\text { C } P-<0.001 \text { OR } 2 \\
\text { T } P=0.03 \text { OR } 1.5\end{array}$ & $\begin{array}{l}C P=0.02 \\
\mathrm{~T} P=0.01\end{array}$ & $C P=0.05$ & \\
\hline $\begin{array}{l}\text { Sitting up } \\
\text { for bowel care }\end{array}$ & $P=0.001$ & & & & & & $\begin{array}{l}\text { Shorter } \\
C P \leqslant 0.001 \\
\text { T } P=0.06\end{array}$ & & $P \leqslant 0.001$ \\
\hline
\end{tabular}

Abbreviations: $C$, cervical; $L / S=$ lumbar/sacral; $O R$, odds ratio; $T=$ thoracic.

All associations are positive except where indicated. 
Table 8 Associations between respondent characteristics and bowel management outcomes (significant results only) ${ }^{\mathrm{a}}$

\begin{tabular}{|c|c|c|c|c|c|c|}
\hline & & $\begin{array}{l}\text { Increasing age } \\
\text { at study }\end{array}$ & $\begin{array}{l}\text { Increasing duration } \\
\text { of injury }\end{array}$ & $\begin{array}{l}\text { Gender (women reported } \\
\text { more in all cases) }\end{array}$ & $\begin{array}{l}\text { Greater density } \\
\text { of lesion }\end{array}$ & $\begin{array}{l}\text { Higher level } \\
\text { of injury }\end{array}$ \\
\hline Total problems reported & $P=$ & & & 0.002 & 0.001 & \\
\hline Duration of bowel care & $P=$ & 0.03 reduced & $<0.001$ & & $<0.001$ & $<0.001$ \\
\hline Rectal prolapse & $P=$ & & 0.04 & & 0.02 & \\
\hline Constipation & $P=$ & & & $<0.001$ & $<0.001$ & 0.03 \\
\hline Haemorrhoids & $P=$ & 0.004 & $<0.001$ & & $<0.001$ & $<0.001$ \\
\hline Surgery & $P=$ & $<0.001$ less & $<0.001$ less & & & \\
\hline Reduced flexibility & $P=$ & $<0.001$ & & & $<0.001$ & $<0.001$ \\
\hline Abdominal distension & $P=$ & 0.03 less & & $<0.001$ & & $<0.001$ \\
\hline Incontinence & $P=$ & & & & $<0.001$ & $<0.001$ \\
\hline Abdominal pain & $P=$ & 0.004 & & 0.001 & & 0.02 \\
\hline Frequency of bowel care & $P=$ & $<0.001$ reduced & 0.001 reduced & & 0.001 & $<0.001$ \\
\hline
\end{tabular}

${ }^{\mathrm{a} A l l}$ associations are positive except where stated.

The efficacy of rectal stimulants also requires further exploration. The contribution of diet remains unclear; a strong association with abdominal distension (see Table 8) suggests that the dietary interventions used may contribute to this problem.

Laxative use among SCI individuals is widespread, though they may be ineffective. ${ }^{9}$ More than half of laxative users reported constipation. It is not clear whether this is because the laxatives were ineffective or were successful, but individuals still regarded themselves as constipated because they continued to need laxatives.

In clinical practice, the importance of regular, frequent bowel management is often emphasized; an association between decreasing frequency of management or lack of a regular routine and reported constipation supports this. However, a rigid routine may reduce quality of life, and very frequent care is associated with dissatisfaction. Frequency should be determined by individual needs and response to bowel care and allow as much flexibility as possible.

A relatively low incidence of faecal incontinence emphasizes the general success of care in achieving managed continence, but may obscure the real cost of achieving continence. The impact of time spent on bowel care was significant, as reported in earlier studies; ${ }^{4,5}$ both greater frequency and duration were significantly associated with dissatisfaction and greater effect on daily life. Time spent on bowel care may be an important outcome measure of the success of bowel management from the patient's perspective in both rehabilitation and chronic settings.

Bowel management has been identified as a stimulus for autonomic dysreflexia ${ }^{10}$ but was a frequent complication of bowel care for very few respondents; $9.5 \%$ of those with injuries above T7. Fifteen individuals with SCI below this level also reported dysreflexic symptoms.

Although haemorrhoids were frequently reported, only $3 \%$ reported banding or injection; haemorrhoids in this population seldom give rise to major complications. Surgical management interventions were notably rare. Only seven individuals reported a sacral anterior root stimulator despite its availability for several decades and positive impact on bowel management. ${ }^{11}$ One individual reported an antegrade continence enema; these are common in spina bifida children and have been performed successfully in SCI adults. $^{12}$ Colostomy for bowel management after SCI has been found to be effective, ${ }^{13}$ but was reported by only $2.4 \%$ of respondents (excluded from analysis). The low level of surgical intervention merits exploration as it is possible that some potentially helpful operations are currently under used.

Significant associations were identified between some interventions and problems, some of which may be explained through the mediation of constipation; stimulation of the autonomic nervous system during digital interventions may also play a part. It seems likely that problems with bowel management are to some extent the product of the interventions used; however, until new improved interventions are developed these side effects remain significantly preferable to non-management. Lack of association with duration of injury supports earlier suggestions that individuals with problems could be identified early, allowing swifter access to non-conservative methods of treatment. ${ }^{14}$

One-third of respondents needed assistance with bowel management, similar to levels in Denmark, ${ }^{1}$ Australia ${ }^{5}$ and somewhat less than that in America (53\%). ${ }^{15}$ Involvement of partners in bowel care is generally discouraged. The fact that $30 \%$ of assistance in this study was given by partners may reflect inadequacy in community health-care provision. Needing assistance significantly increased the impact of bowel dysfunction; those receiving complete care were less satisfied than those receiving partial care perhaps due to the very personal nature of the care and the implicit breaking of social taboos. Bowel care has considerable implications for all involved; $50 \%$ of individuals who require assistance spend more than $30 \mathrm{~min}$ on bowel management, $70 \%$ of those assisted by personal carers. This has a negative impact on life activities for the SCI individual, but also has implications for carers and community nursing services.

As reported elsewhere, ${ }^{4}$ individuals with cervical lesions experienced the greatest burden with bowel management. Physically, this may be related to loss of sympathetic input to the colon, greatly increased transit times and loss of control of abdominal musculature. ${ }^{16,17}$ However, differences in management and outcomes may also reflect attitudes among 
carers who are often reluctant to use 'invasive' interventions, for example digital evacuation, despite approval of professional organizations. ${ }^{18}$ This reluctance may necessitate greater use of rectal stimulants and oral laxatives, resulting in longer management time. Limited availability of carers may explain the reduced frequency and flexibility seen in dependent individuals.

Interesting gender differences emerged, as in the general population, women reported more constipation, abdominal pain and distension than men. Incontinence was no higher among women, but their greater tendency to wear pads and higher rating of impact on life suggest that they may be more anxious regarding bowel dysfunction than men.

Earlier studies have suggested a relationship between increasing age and duration of injury and changes in bowel function. ${ }^{14}$ Here they were associated with greater laxative use, stronger rectal stimulants and an increased use of digital evacuation, suggesting that reflex bowel function does deteriorate over time. However, greater duration of injury was not associated with more problems, surgery was more likely earlier than later post-injury, faecal incontinence reduced over time and the use of stimulant laxatives did not increase. Greater age, however, was associated with increased use of stimulant and other laxatives, suggesting that deterioration in bowel function over time may be associated with age-related changes in the bowel and diminishing mobility rather than the effects of prolonged stimulant laxative use or increasing duration of SCI alone. Changes in bowel management and function with age after SCI have been reported, ${ }^{16}$ but are also reported in the nonSCI population. ${ }^{19}$ Changes in function may be more significant after SCI due to other disability-related factors.

The impact of bowel dysfunction has been ranked as significant in this and earlier studies, ${ }^{4,16}$ but surprisingly few respondents reported dissatisfaction. Very low expectations of bowel management and lack of awareness of the admittedly limited choices available, such as transanal irrigation, ${ }^{20}$ may provide some explanation. This may be compounded by the lack of clinical services with specialist staff dedicated to optimizing bowel management, thereby denying SCI individuals a pathway through which to seek assistance with this aspect of care. Satisfaction may not be a useful outcome measure for bowel care after SCI.

The results of this study may not generalize to the entire chronic SCI population as they are from just less $50 \%$ of patients at a single centre. However, given this caveat, it seems likely that they apply to substantial numbers of people with SCI.

\section{Conclusions}

Managing bowel function in the community after SCI involves multiple interventions and considerable time and impacted on life most compared with other SCI-related impairments in these chronically injured individuals. This and the associations between interventions and problems demand further exploration of bowel management to reduce the impact on quality of life, minimize side effects and increase the choice of management strategies available. The aim of professionals engaged in this area should be to develop, with the patient, an individualized programme reflecting the complex interplay of SCI, dependency and individual characteristics of each patient, using minimum interventions and time to deliver effective care.

\section{Acknowledgements}

This study was funded by an Action Medical Research Training Fellowship award to M Coggrave.

\section{References}

1 Krogh K, Nielsen J, Djurhuus JC, Mosdal C, Sabroe S, Laurberg S. Colorectal function in patients with spinal cord lesions. Dis Colon Rectum 1997; 40: 1233-1239.

2 Stiens S, Bergman S, Goetz LL. Neurogenic bowel dysfunction after spinal cord injury: clinical evaluation and rehabilitative management. Arch Phys Med Rehabil 1997; 78 (3 Suppl): S86-S102.

3 Krogh K, Mosdal C, Laurberg S. Gastrointestinal and segmental colonic transit times in patients with acute and chronic spinal cord lesions. Spinal Cord 2000; 38: 615-621.

4 Glickman S, Kamm M. Bowel dysfunction in spinal-cord-injury patients. Lancet 1996; 347: 1651-1653.

5 Ng C, Prott G, Rutkowski S, Li Y, Hansen R, Kellow J et al. Gastrointestinal symptoms in spinal cord injury: relationships with level of injury and psychologic factors. Dis Colon Rectum 2005; 48: 1562-1568.

6 Correa GI, Rotter KP. Clinical evaluation and management of neurogenic bowel after spinal cord injury. Spinal Cord 2000; 38: 301-308.

7 Haas U, Geng V, Evers G, Knecht H. Bowel management in patients with spinal cord injury - a multicentre study of the German speaking society of paraplegia (DMGP). Spinal Cord 2005; 43: 724-730.

8 Zejdlik CP. Management of Spinal Cord Injury, 2nd edn. Jones and Bartlet: Boston, 1992, 552p.

9 Harari D, Minaker K. Megacolon in patients with chronic spinal cord injury. Spinal Cord 2000; 38: 331-339.

10 Kirschblum SC, House JG, O'Connor KC. Silent autonomic dysreflexia during a routine bowel program in persons with traumatic spinal cord injury: a preliminary study. Arch Phys Med Rehabil 2002; 83: 1774-1776.

11 Creasey GH, Grill JH, Korsten M, U HS, Betz R, Anderson R et al. An implantable neuroprosthesis for restoring bladder and bowel control to patients with spinal cord injuries: a multicentre trial. Arch Phys Med Rehabil 2001; 82: 1512-1519.

12 Teichman JM, Zabihi N, Kraus SR, Harris JM, Barber DB. Long-term results for Malone antegrade continence enema for adults with neurogenic bowel disease. Urology 2003; 61: 502-506.

13 Branagan G, Tromans A, Finnis D. Effect of stoma formation on bowel care and quality of life in patients with spinal cord injury. Spinal Cord 2003; 41: 680-683.

14 Lynch AC, Wong C, Anthony A, Dobbs B, Frizelle F. Bowel dysfunction following spinal cord injury: a description of bowel function in a spinal cord-injured population and comparison with age and gender matched controls. Spinal Cord 2000; 38: 717-723.

15 Kirk P, King R, Temple R, Bourjaily J, Thomas P. Long-term followup of bowel management after spinal cord injury. SCI Nurs 1997; 14: 56-63.

16 Harari D, Sarkarati M, Gurwitz J, McGlinchey-Berroth G, Minaker $\mathrm{K}$. Constipation-related symptoms and bowel program concerning individuals with spinal cord injury. Spinal Cord 1997; 35: 394-401.

17 Lynch AC, Antony A, Dobbs BR, Frizelle FA. Bowel dysfunction following spinal cord injury. Spinal Cord 2001; 39: 193-203. 
18 Addison R, Smith M. Digital Rectal Examination (DRE) - Manual Evacuation of Faeces. Guidelines on the Role of the Nurse. Royal College of Nursing, London, UK, 1999.

19 Madsen-Jan L, Graff J. Effects of ageing on gastrointestinal motor function. Age Ageing 2004; 33: 154-159.
20 Christensen P, Bazzocchi G, Coggrave M, Abel R, Hultling C, Krogh $\mathrm{K}$ et al. Treatment of fecal incontinence and constipation in patients with spinal cord injury - a prospective, randomized, controlled, multicentre trial of transanal irrigation vs conservative bowel management. Gastroenterology 2006; 131: 738-747.

\section{Appendix 1}

\section{About you}

\begin{tabular}{|l|}
\hline Date of birth \\
\hline ' $\square$ Male \\
\hline Date of injury or onset of spinal cord damage \\
\hline Level of your spinal cord injury or damage \\
\hline Is your spinal injury \\
' $\square$ Complete $2 \square$ Incomplete $\square$ Don't know \\
\hline
\end{tabular}

If you would like more information about the rest of this research project please complete the section below:

NAME.

Address

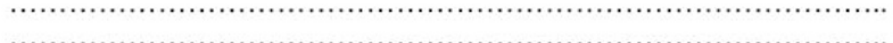

n.t.

等,

Telephone.

\begin{tabular}{|l|l|}
\hline Received & \\
\hline Info date & \\
\hline Data entered & \\
\hline Tel con & \\
\hline
\end{tabular}




\section{About your Bowel Care}

1. Are you satisfied with your bowel management routine? Please tick one box

1. $\square$ Yes, very satisfied.
If Yes, satisfied.

If you ticked box 1 or 2 please go to Question 3

3. $\square$ No, I'm dissatisfied 4. ${ }^{4} \square$ No, I'm very dissatisfied

If you ticked box 3 or 4 please continue with Question 2

2. If you ticked NO (box 3 or 4) in Question 1 please explain why and then continue with the remaining questions.

3. Do you regulate your diet to help with bowel management?

$2 \square$ No $\quad 1 \square$ Yes- please explain

4. How much do you usually drink each day?

About $1 / 2$ a litre $\quad 2 \square$ llitre $\quad 3 \square \quad 1-2$ litres $\quad 4 \square$ More than 2 litres

5. What steps do you usually use to empty your bowel? Tick all that you use

Drink/food before bowel management $\square$ Massaging or rubbing your tummy

Touching the skin around the anus

Stimulation - putting a finger inside the anus and circling

Manual evacuation - using a finger to $\square$ Suppositories - what kind and how remove stool from the bowel many?

Laxatives - what kind and how much? $\square$ Enemas - what kind?

Other steps. Please explain.

6. How long have you been managing your bowel this way?

$\square$ Less than 6 months $2 \square$ Less than 1 year $\quad 3 \square$ Upto 5 years 4 Longer 


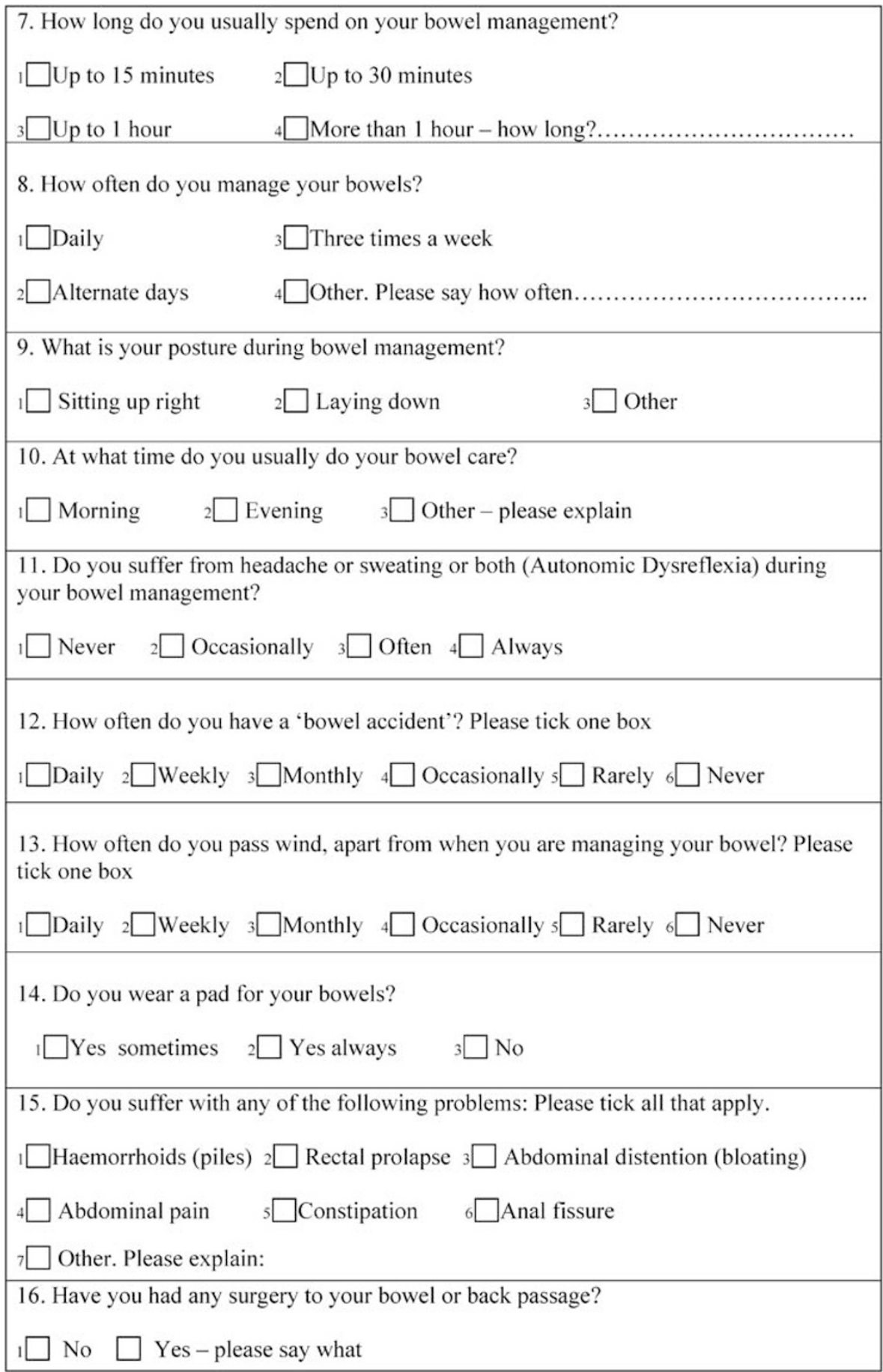




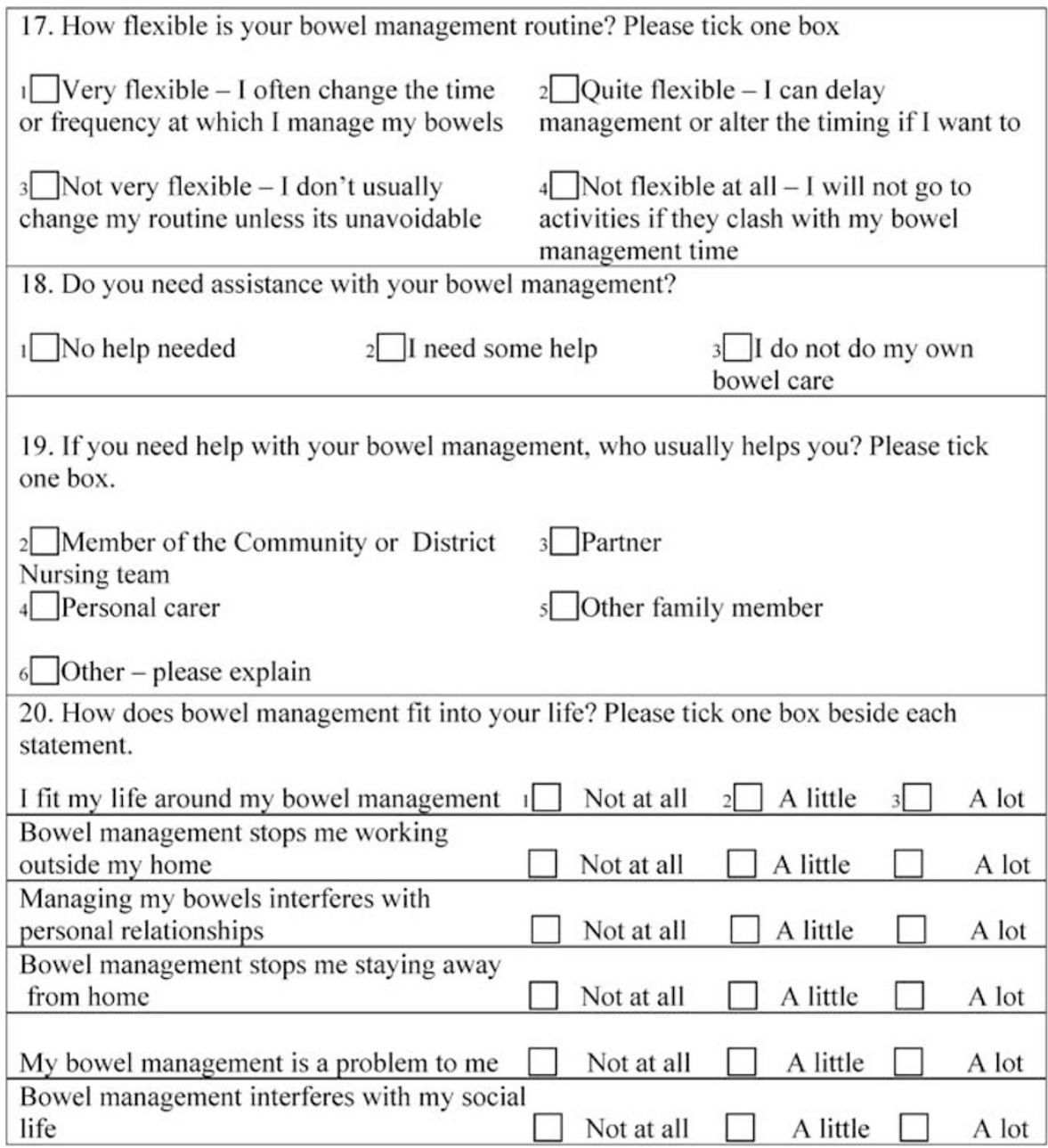

21. How much does bowel management affect your life compared to other aspects of Spinal Cord Injury?

Please give each of the following items a score between 1 and 10 , where 10 is the worst effect and 1 is the least.

If you feel an item does not apply to you please put a cross in the box.

\begin{tabular}{|l|l|}
\hline Managing my bladder & \\
\hline Changes in my sexual function & \\
\hline Using a wheelchair & \\
\hline Taking care of my skin & \\
\hline Managing my bowel & \\
\hline Living with chronic pain & \\
\hline Living with spasticity & \\
\hline
\end{tabular}

Thank you very much for completing this questionnaire. Your help is valuable.

If there is any thing else you would like to tell us about your experience with bowel management please do so here. 